\title{
LA POLIITICA INTERNACIONAL NORTEAMERICANA Y LAS ORIENTACIONES AL ESTABLECIMIENTO DE UNA AUTORIDAD POLÍTICA INTERNACIONAL SEGÚN "CARITAS IN VERITATE"
}

Eduardo Calcín Figueroa*

\begin{abstract}
RESUMEN
El 01 de setiembre del 2010, Barack Obama anunció oficialmente el fin de la misión de combate en Irak. Los soldados norteamericanos regresaron a sus hogares después de siete años y medio en el territorio iraquí. Se calificó este hecho, como un "momento histórico". Pero, las palabras del portavoz del Departamento de Estado Norteamericano, P. J. Crowley "esto no supone el fin de la misión estadounidense en el país" dan lugar al análisis. Esto hacemos en el presente artículo. A su vez, el anuncio del ex presidente norteamericano G. Bush de establecer "nuevo orden mundial" nos lleva a considerar si éste se encuentra en consonancia con la voluntad del papa Benedicto XVI cuando propone el establecimiento de una "Autoridad política internacional" en su última encíclica social Caritas in veritate.
\end{abstract}

\section{PALABRAS CLAVE:}

Islam, kurdos, chiitas, intifada, yihad, hamas, hezbolá, musulmán.

\section{THE INTERNATIONAL POLITICS OF THE UNITED STATES AND GUIDELINES FOR CONSTITUTING AN INTERNATIONAL POLITICAL AUTHORITY AS CARITAS IN VERITATE}

\begin{abstract}
September 01, 2010, Barack Obama officially announced the end of the combat mission in Iraq. American soldiers returned home after seven years in Iraqi territory. It described this fact as a "historic moment". But the words of the spokesman of U.S. State Department, P. J. Crowley "This is not the end of the U.S. mission in the country "giving rise to the analysis. This we do in this article. In turn, the announcement of former U.S. President G. Bush to establish "new world order" leads us to consider whether it is in line with the will of Pope Benedict XVI when he proposes the establishment of an "international political authority" in the latest social encyclical, Caritas in veritate.

\section{KEY WORDS:}

Islam, Kurds, Shiites, intifada, jihad, Hamas, Hezbollah, Muslim.

\footnotetext{
* Licenciado y Magíster en Teología por la Facultad de Teología Pontificia y Civil de Lima. Egresado de Maestría en Historia de la Filosofía de la Universidad Nacional Mayor de San Marcos. Actualmente cursa estudios doctorales en Psicología Educacional en la Universidad Nacional de Educación Enrique Guzmán y Valle. Se desempeña como Profesor de Filosofía y Teología en la UNIFÉ, la Universidad Marcelino Champagnat y del Instituto de Teología Pastoral de la Diócesis de CHOSICA.
} 


\section{El conflicto de Irak:}

Obama da la guerra de Irak por terminada. El presidente de EE.UU. se dirige a la nación para proclamar el fin dela misión de combate - La Casa Blanca reconoce que queda mucho por hacer.

"Esta noche anunció que la misión de combate norteamericana en Irak ha terminado. La operación Libertad Iraquí ha acabado y el pueblo de Irak tiene ahora la responsabilidad principal de mantener la seguridad de su país". De este modo, Barack Obama dio por concluida la guerra de Irak, siete años y cinco meses después de su comienzo, en un discurso televisado a la nación desde la Casa Blanca. El País. Jueves 2 de setiembre de 2010.

\section{L} a actitud norteamericana con el anuncio del fin de la guerra con Irak por parte del presidente norteamericano Barack Obama parece marcar el reinicio de una nueva política internacional de Estados Unidos en el nuevo contexto mundial. Medios de comunicación y analistas políticos han resaltado el tono como el presidente norteamericano Barack Obama ha anunciado el fin de la operación Libertad iraquí, en un tono sobrio y sin triunfalismos.

El regreso de las tropas norteamericanas ocurre después de casi siete años y medio de ocupación del territorio de Irak, en el que más de 4,400 soldados norteamericanos han perdido la vida y más de 100,000 iraquíes entre soldados y civiles han muerto, en el balance de una guerra injustificada e injustificable.

Tiempo atrás diversas declaraciones papales y vaticanas dejaban escuchar su voz por un rechazo total de una guerra porque detrás de ella habían razones políticas (riesgo de inestabilidad en Oriente Próximo) y jurídicas (falta de acuerdo en la $\mathrm{ONU}$ ) que tendrían un saldo nefasto para la seguridad y orden internacionales. El papa Juan Pablo II en una carta dirigida al presidente George Bush, manifiesta:
Deseo ahora repetir mi firme convicción de que es muy difícil que la guerra lleve a una solución adecuada a los problemas internacionales y que, aunque se pudiera resolver momentáneamente una situación injusta, las consecuencias que con toda probabilidad se derivarían serían devastadoras y trágicas. No podemos ignorar que el uso de las armas, y especialmente los armamentos altamente sofisticados de nuestros días, provoquen, además de sufrimiento y destrucción, nuevas y tal vez peores injusticias ${ }^{32}$.

El arzobispo Jean-Louis Tauran, secretario del Vaticano para las Relaciones con los Estados, en su discurso a los Organismos internacionales elevaba su voz firmemente el 23 de diciembre de 1991, manifestando: "Es necesario hacer lo posible para que este ataque no tenga lugar". Y en forma decidida el papa Juan Pablo II, en un discurso a los representantes de los 117 países con los que el Vaticano mantiene relaciones diplomáticas, pronunció su famoso: "iNo a la guerra!", refiriéndose explícitamente a Irak por primera vez (Discurso de Juan Pablo II al cuerpo diplomático. Vaticano, 13 de enero de 2003).

El costo de la guerra ha tenido un alto precio que no sólo tendrá que pagar Estados Unidos sino también el resto de

32 Carta de Juan Pablo II a George Bush, Presidente de EE.UU. en razón del Conflicto del Golfo Pérsico. Vaticano, 15 de enero de 1991 . 
las naciones. Dado que, una guerra mucho más que vencedores y vencidos deja como saldo: hombres muertos y heridos, familias destruidas, escombros de una sociedad que se levanta en base al esfuerzo de toda una comunidad; pero sobretodo, heridas abiertas y resentimientos que quiebran la esperanza de una comunidad internacional fraterna.

\section{Crónica de una guerra}

El factor desencadenante de la Guerra del Golfo fue la invasión de las tropas iraquíes al emirato árabe de Kuwait el 2 de agosto de $1990^{33}$. Al amanecer de ese día, las tropas de Irak cruzaron la frontera de Kuwait con vehículos armados e infantería, ocupando puntos y puestos estratégicos en todo el país, incluyendo el palacio del Emir. El ejército de Kuwait fue rápidamente vencido, aunque opuso mayor resistencia en el palacio del Emir y los alrededores del cuartel general de la fuerza aérea de Kuwait. Los soldados iraquíes detuvieron a miles de turistas occidentales como rehenes para usarlos luego como escudo de negociaciones. Frente a tales acontecimientos, la comunidad internacional de las Naciones Unidas reaccionaron inmediatamente condenando el ataque premeditado de Irak a Kuwait resolviendo sanciones económicas y la constitución de bloqueos marítimos y aéreos, bajo el mandato de retirar sus tropas de territorio kuwaití.

El 1 de diciembre del mismo año, el presidente norteamericano George Bush propuso públicamente la celebración de negociaciones directas con el presidente iraquí Saddam Hussein para buscar una solución pacífica al conflicto, con intercambio de visitas de los ministros de Asuntos Exteriores de ambos países. Baker y Aziz se reunieron en Ginebra el 9 de enero de 1991, sin llegar a un acuerdo. Se celebraron ruedas de negociaciones para solucionar pacíficamente el conflicto pero que fracasaron, como aquella reunión celebrada el día 13 de enero entre Pérez de Cuéllar y Saddam Hussein.

El día 7 de enero Estados Unidos que ya había condenado la invasión iraquí, inició un gran despliegue militar, enviando fuerzas militares a Arabia Saudita y al Golfo como una forma de llamar la atención a Saddam Hussein y darle a conocer que su maniobra en contra de Kuwait no dejaría indiferentes a la comunidad internacional. En los meses siguientes se fueron uniendo ejércitos y fuerzas militares de Canadá y Australia y de los países europeos occidentales, al ser acordado el bloqueo por la U.E.O (Unión Europea Occidental): Gran Bretaña, Francia, Italia, España, Holanda, Bélgica, Alemania, Dinamarca, Noruega y Grecia; así como de algunos países árabeislámicos: la propia Arabia Saudí y los Emiratos Árabes Unidos, además de Egipto, Siria, Marruecos, Pakistán y Bangladesh.

Habiéndose realizado esfuerzos por encontrar una solución negociada a nivel diplomático, el ataque comenzó la noche entre el 16 y el 17 de enero de 1991, cuando la fuerza multinacional aliada ini-

33 Durante varios años Irak había estado reclamando Kuwait, respaldándose en el hecho de que este territorio era parte de Irak en la época del Imperio Otomano, específicamente, parte de la provincia de Basora. En meses anteriore ambos países habían tenido una serie de disputas; Irak alegaba que desde 1980, Kuwait había estado robándole petróleo desde su yacimiento de Rumaylak (situado bajo ambos territorios). Por otra parte, Irak dependía del valor del combustible para pagar su deuda externa contraída en la guerra contra Irán (casi 40,000 millones de dólares con intereses de 3,000 millones por año), se sentía afectado por la superproducción de Kuwait y otros países del Golfo, que mantenían un precio bajo del insumo. Además, otra posible causa era la necesidad iraquí de acceder al Golfo Pérsico desde su puerto de Umm Qasr. Finalmente, es posible que el presidente Saddam Hussein, necesitara una rápida conquista para mejorar en algo su bajo prestigio y perfilarse como líder del mundo árabe. 
cia la operación "Tormenta del desierto", dirigida por Estados Unidos. Se bombardean los territorios de Irak y Kuwait. La respuesta iraquí no se hizo esperar, lanzó una contraofensiva contra las poblaciones de Arabia Saudita e Israel. Y la amenaza de un ataque con armas químicas se comenzó a propalar creándose el pánico entre los pobladores civiles. Desde el punto de vista bélico, los misiles lanzados por Irak contra Israel, cumplieron una función psicológica y de amedrentamiento más que de destrucción. Se trataba de lanzaderas móviles, generalmente camiones que se encontraban en movimiento constante y que eran difícilmente de hallar por la aviación o la artillería aliada. Al mismo tiempo, se informó de una gran marea negra de petróleo procedente de Kuwait, derramada de forma intencionada por los iraquíes que se estaba extendiendo sobre el Golfo Pérsico dañando de manera irreversible el medio natural.

Una segunda y breve fase de la guerra se inició el 23 de febrero de 1991, duró cinco días y consistió en una dura ofensiva por parte de los aliados invadiendo Kuwait y el sur de Irak. El ejército iraquí se retiró derrotado y con un gran número de desertores que sobrevivían en una condición casi insostenible. El mismo día 27 de febrero el presidente G. Bush anunció el final de la guerra entre los aliados e Irak, reestableciéndose inmediatamente el gobierno del emirato en Kuwait. Mientras tanto, el gobierno norteamericano alentó al pueblo iraquí a derribar a S. Hussein del poder e introducir una serie de reformas democráticas en Irak, al que impuso una serie de sanciones que fue aceptada por este país.

\section{Análisis de la intervención norte- americana en la Guerra del Golfo}

Finalizada la guerra con Irak la intervención de Estados Unidos no se dio por concluida. Se constituyó en dicho país un contingente numeroso de soldados compuesto por las fuerzas multinacionales que más allá de garantizar la paz y reestablecer el orden, buscan rediseñar el orden político del Medio Oriente, basado en el control político militar.

Dicha presencia, genera respuestas de rechazo entre amplios sectores de la población, y las fuerzas de ocupación asumen un papel de espectadores frente a los actos de violencia desencadenados por los kurdos ${ }^{34}$ (en el norte) y chiitas ${ }^{35}$ (en el sur) que buscaban debilitar y derrocar a Saddam Hussein. El saldo de esta guerra en niveles cuantificables para el pueblo iraquí fue desastrosa: se destruyó la red de transportes, telecomunicaciones e industria; escasez de alimentos y las enfermedades son las principales causas de las muertes infantiles. En los primeros años después del conflicto, según informa las Naciones Unidas murieron más de un millón de personas, de las cuales la mitad eran niños menores de cinco años. También se incrementaron los casos de cáncer como consecuencia del uranio empobrecido dispersado por los misiles aliados.

En este contexto y drama situacional la preocupación de EE.UU no se encontraba en la pacificación de un país o la reconstrucción de toda una nación como consecuencia de la guerra; sino en derro-

34 Los kurdos constituyen un pueblo indoeuropeo que habitan en la región montañosa del Kurdistán, -se asentaron en el espacio que actualmente ocupan hacia el 2500 a.C-, en el suroeste de Asia, repartida principalmente entre los estados de Irak, Turquía, e Irán. Los kurdos son en su mayoría musulmanes sunies, aunque una importante minoría todavía sigue la religión tradicional kurda, el yazidismo.

35 Los chiitas son una corriente interna del Islam que propugnaron tras la muerte de Mahoma que el sucesor del profeta debería ser de su mismo clan. Sus miembros son mayoritariamente de clase popular y por tanto han sido marginadas. 
car el régimen de S. Hussein y exterminar a sus aliados que según versiones norteamericanas habían encontrado refugio en Siria, que escondía armas de destrucción masiva e incitaba al terrorismo.

Las palabras de G. Bush expresadas en la primera semana de iniciada la crisis del Golfo Pérsico al afirmar el establecimiento de un "nuevo orden mundial", dibujan de cuerpo entero los intereses norteamericanos en el Medio Oriente y su rol protagónico en el pano rama político mundial. Este supuesto "nuevo orden mundial" se hará no bajo los lineamientos consensuados entre los países que conforman las Naciones Unidas; sino según los intereses políticos y económicos de los Estados Unidos. Así, en la Guerra del Golfo los intereses norteamericanos no acababan con el derrocamiento de Saddam, ese sólo será la punta del iceberg porque la incursión norteamericana tendrá secuelas más allá de las fronteras de Irak y que apuntan a Siria. Pero, el verdadero objetivo no es Siria, sino las facciones radicales islámicas que huyen de la persecución norteamericana y que anhelan el establecimiento del Estado palestino.

Estados Unidos busca aislar a los grupos palestinos radicales que se oponen a un acuerdo con Israel, como $\operatorname{Hamas}^{36}$ y la Yihad $^{37}$ islámica. La derrota de Irak servirá a esto. La presión a Siria, que ha venido actuando como punto de apoyo para estos grupos radicales en los territorios ocupados o del Hezboláa ${ }^{38}$ en el sur del Líbano, se enmarca dentro de esta estrategia. Los esfuerzos norteamericanos alcanzan una primera victoria al lograr someter a Yasir Arafat y llevarlo aceptar a Mahmud Abbas como primer Ministro y de su gabinete, de marcada orientación pronorteamericana, al frente de la Autoridad Nacional Palestina. La toma de posición del gabinete de Abbas es la condición que puso Bush para publicar la "hoja de ruta", un plan de paz que prevé la creación de un estado palestino antes de 2005, cosa que hasta ahora no se ha dado, porque la "hoja de ruta" más que un plan de seguridad es un plan político para desactivar la intifada ${ }^{39}$.

La política norteamericana persecutoria en el intento de desarticular la intifada mediante su penalización política de la O.L.P. (Organización para la Liberación de Palestina) y de la población palestina, logrará acentuar su presencia en el Medio Oriente y marcar el rumbo de las negociaciones.

36 Es el Movimiento de resistencia Islámico; se trata de una organización política y militar palestina que se declara como yihadista, nacionalista e islámica. Su objetivo fundamental es el establecimiento de un estado islámico en la región histórica de Palestina, que comprendería los actuales Israel, Cisjordania y la Franja de Gaza, con capital en Jerusalén. Hamas ha sido declarada organización terrorista por la Unión Europea, los Estados Unidos, Israel, Japón, Canadá y Australia. Desde su creación en 1987 hasta la actualidad, las distintas organizaciones que forman parte de Hamas se han convertido en objetivos prioritarios de las operaciones militares israelíes.

37 Es un grupo terrorista islamista cuyos intereses es el establecimiento de un estado islámico y atacar intereses estadounidenses e israelíes tanto en Egipto como en el extranjero.

38 También llamado Hizbullah o Hezbollah, es una organización islamista libanesa prosiria y proiraní que cuenta con un brazo político y otro paramilitar. Fue fundado en Irán en 1979 y en el Líbano en 1982 como respuesta a la ocupación Israel. Hezbolá recibe armas, capacitación y apoyo financiero de Irán y cuenta con la aprobación de Siria.

39 Significa agitación, levantamiento, es el nombre popular de dos rebeliones de los palestinos de Cisjordania y la Franja de Gaza contra Israel. Ambas intimadas empezaron como campañas de resistencia de los palestinos y fueron intensificándose en un ciclo de violencia de atentados terroristas. Los objetivos que persiguen la intifada son: Combatir la ocupación de los territorios palestinos por parte de Israel o en su defecto la destrucción del Estado de Israel. 


\section{La constitución de una "Autoridad Política Mundial" según la Caritas in Veritate}

Los sucesos desarrollados en el Medio Oriente, sobretodo a raíz de la Guerra del Golfo nos llevan a pensar en la inestabilidad política que se cierne sobre dichos territorios y su amenaza al mundo entero. Los Estados Unidos al intervenir directamente en el conflicto bilateral Irak-Kuwait ha antepuesto sus propios intereses políticos y económicos, a los intereses de la propia región y la solución de graves problemas como la determinación de los legítimos derechos que le corresponde a los palestinos en el territorio de la Palestina por razones históricas.

Terminada la Guerra del Golfo el país de Irak no terminaba de desangrarse por diversas razones: 1) La resistencia de Saddam Hussein de permanecer en el poder, 2) la represión de los soldados norteamericanos y fuerzas de coalición al pueblo iraquí, como su inoperancia ante el enfrentamiento de las facciones radicales islámicas y, 3) el silencio de las Naciones Unidas para tomar acciones inmediatas y remediar la crisis desatada.

Actualmente la situación está en que el presidente norteamericano Barack Obama anunció al mundo entero el final de la misión de combate norteamericano en Irak y la responsabilidad que tiene el pueblo iraquí en mantener su propia seguridad. Los términos expresados por Obama no tenían la solemnidad de su predecesor G. Bush declarando el nacimiento de "un nuevo orden mundial".

No se puede construir "un nuevo orden mundial" sobre los escombros de un país que ha sido reducido a la era preindustrial y naciones que en transcurso de los años han experimentado dramáticamente la incursión de la política norteamericana: por ejemplo, en 1953 la CIA organiza un golpe de Estado en Irán, entre 1958 a 1975 se lleva a cabo la guerra de Vietnam, en 1961 la CIA entrena tropas anticastristas para invadir Cuba, en 1973 Augusto Pinochet toma el poder en un golpe de Estado apoyado por la CIA, etc. Las intervenciones de Estados Unidos en el resto del mundo fueron numerosas desde 1775, por distintas causas. Esto comprende intervenciones militares directas (guerras, envío de fuerzas) e indirectas (apoyo logístico de gobiernos, servicio de espionaje). Así, la política norteamericana respalda sus propios intereses en la región donde interviene y no el bienestar de los hombres que la habitan.

Indudablemente, el panorama político siempre será complejo y por ello, en ocasiones instituciones políticas de carácter internacional podrán ser invocados para resolver una situación conflictiva en un determinado país. Pero, la intervención de un país o países como supuestos árbitros para resolver una crisis entraña el peligro de responder a intereses particulares. Si se quiere construir realmente una comunidad fraterna donde los hombres coexistan con respeto de sus derechos fundamentales, debemos sincerar los foros de diálogo entre las naciones, porque toda la humanidad está alienada cuando se entrega a proyectos exclusivamente humanos a ideologías y utopías falsa (CV. 53).

Desde esta realidad, el papa Benedicto XVI en su encíclica Caritas in veritate plantea el establecimiento de una "Autoridad política internacional" (CV.67), constituida participativamente por la "comunidad política internacional", que estructure el funcionamiento del poder y busque cohesionar las estructuras de convivencia so- 
cial en su más alto grado ${ }^{40}$. La búsqueda del bien común de los pueblos ha de ser su más anhelada aspiración, y sólo en él encontrará su justificación plena y sentido del que derivará su autoridad moral. A su vez, la comunidad política internacional posibilita la participación, conocimiento y debate sobre la pluralidad de pareceres en un amplio sentido democrático, que se basa en la libertad y sentido de responsabilidad. Así, esta autoridad deberá estar regulada por el derecho, atenerse a los principios de subsidiaridad y de solidaridad, estar ordenada a la realización del bien común (CV. 67). Es deber de la autoridad política en general dirigir con auténtico sentido de responsabilidad social a los pueblos para que elijan su propio destino basado en el respeto por la persona humana y sus instituciones que resguardan la plena vigencia de todos los derechos y libertades fundamentales. Es indispensable una autoridad que dirija la acción de todos hacia el bien común, no mecánica o despóticamente, sino obrando principalmente como una fuerza moral, que se basa en la libertad y en el sentido de responsabilidad de cada uno (GS 74). La sociedad civil considerada como fundamento de la autoridad política se convierte así no en un apéndice o variable de la comunidad política; al contrario, tiene ella la preeminencia, ya que es precisamente la sociedad civil la que justifica la existencia de la comunidad política.

En un nivel internacional es la comunidad de las naciones quienes deben tomar los acuerdos de manera conjunta, considerando el bien común para cada país atendiendo a su pasado histórico, sus posibilidades económicas para desa- rrollarse y la estructuración de un poder político representativo de las mayorías. De aquí, que es muy importante la presencia de un organismo internacional: Ante el imparable aumento de la interdependencia mundial, y también en presencia de una recesión de alcance global, se siente mucho la urgencia de la reforma tanto de la Organización de las Naciones Unidas como del sistema económico y financiero internacional, para que se dé una concreción real al concepto de familia de naciones (CV. 67).

Se debe prevenir que se repitan historias pasadas y experiencias ya vividas, debemos considerar que las sociedades tecnológicamente avanzadas no deben confundir el propio desarrollo tecnológico con una presunta superioridad cultural (CV. 59). Cada nación posee sus propias raíces históricas y culturales, que deben considerarse y respetarse.

Por otro lado, concretamente la situación política en el Medio Oriente es difícil y peligrosa por la presencia de grupos extremistas de talante religioso que muchas veces hacen inviable el diálogo y los acuerdos entre los representantes de las naciones. Por ello, el Papa Benedicto XVI advierte: 'No faltan actitudes religiosas y culturales en las que no se asume plenamente el principio del amor $y$ de la verdad, terminando así por frenar el verdadero desarrollo humano $e$ incluso por impedirlo' (CV 55).

No cabe duda que la religión es un elemento que cohesiona a todo un pueblo, le concede identidad y alienta en la construcción de un proyecto a futuro. Pero, el fundamentalismo religioso puede

40 "Las Naciones Unidas encarnan las aspiraciones a "un grado superior de ordenamiento internacional" (Juan Pablo II, Sollicitudo rei sociales, 43) inspirado y gobernado por el principio de subsidiariedad, y por lo tanto capaz de responder a las demandas de la familia humana mediante la unión. Las normas internacionales ya través de estructuras capaces de armonizar el día a día de desarrollo de la vida de los pueblos" Benedicto XVI, Discurso en la reunión con los miembros de la Asamblea General de la Organización de las Naciones Unidas. Nueva York, 18 - IV - 2008. 
convertirse más que un elemento positivo que ayude a impulsar los esfuerzos a impedir o retrasar la paz y el progreso ${ }^{41}$. Así, el discernimiento sobre la contribución de las culturas y de las religiones es necesario para la construcción de la comunidad social en el respeto del bien común, sobre todo para quien ejerce el poder político (CV. 55).

Indudablemente que el islamismo es una de las grandes religiones que existen, reúne a más de mil millones de habitantes del globo, siendo una de mayor número de devotos; pero para muchos desconocido en este lado del mundo occidental. Un estudio histórico sobre el islamismo nos lleva a comprender que no siempre los musulmanes tuvieron una actitud de "sumisión a Dios" 42 y respeto hacia aquellos que no compartían su fe. El islamismo desde que surgió en el 622 d.C. fundado por Mahoma (570-632 d.C.) se expandió muy rápidamente dominando a los pueblos mediante la guerra e imponiéndoles la religión musulmana. La "Yihad" (guerra santa) consideraba por algunos el sexto pilar del Islam, sobretodo por una minoría de autoridades musulmanas, ha servido para justificar el uso de las armas y proclamar su imperiosa necesidad de expandirse y fortalecerse en el mundo. La defensa del Islam, de los musulmanes o de sus países frente al enemigo externo puede efectivamente adquirir el carácter de lucha militar o guerra santa, y así se halla en el Corán, donde se anima a combatir contra los infieles si el Islam resulta atacado: Combate en el camino de Dios a quienes te combaten, pero no seas el agresor. Dios no ama a los agresores. Má- talos donde los encuentres, expúlsalos de donde te expulsaron. La persecución de los creyentes es peor que el homicidio: no los combatas junto a la mezquita sagrada hasta que te hayan combatido en ella. Si te combaten, mátalos: esa es la recompensa de los infieles. Si dejan de atacarte, Dios será indulgente, misericordioso (Corán 2:190-192). La interpretación de este texto al haber adquirido diversos matices ha servido para justificar el accionar de ciertas facciones radicales del islamismo; consecuentemente, el mundo occidental tiene una visión sesgada y reduccionista de lo que significa y encierra el islamismo como religión, cultura e historia. Por ello, el papa Benedicto XVI, en otra parte de su encíclica añade: el fundamentalismo religioso por otro lado, impide el encuentro entre las personas y su colaboración para el progreso de la humanidad. La vida pública se empobrece de motivaciones y la política adquiere un aspecto opresor. Se corre el riesgo de que no se respeten los derechos humanos, bien porque se les priva de su fundamento trascendente bien porque no se reconoce la libertad personal (CV 56).

Por ello, incluso trayendo a colación el famoso discurso proferido por el papa Benedicto XVI en Ratisbona, el 12 de setiembre de 2006, donde defiende la necesidad de fortalecer una fe racional, en conformidad con la naturaleza de las cosas y con la propia naturaleza de Dios. No se trata de una fe fundamentalista, ni tampoco de una razón radical; es, en verdad, una fe dirigida hacia el actuar concretamente y conforme a la ley natural y la ley divina: no actuar con el logos es

41 "Quien mata con atentados terroristas cultiva sentimientos de desprecio hacia la humanidad, manifestando desesperación ante la vida y el futuro; desde esta perspectiva, se puede odiar y destruir todo. El terrorista piensa que la verdad en la que cree o el sufrimiento pedecido son tan absolutos que lo legitiman a reaccionar destruyendo incluso vidas humanas inocentes. Juan Pablo II, Mensaje XXXV Jornada Mundial de la Paz, Ciudad del Vaticano, 01 - I - 2002.

42 "Musulmán" es la persona cuyo credo religioso es el Islam. Palabra árabe "muslim" significa "que se somete", es decir, completa sumisión a la voluntad de Dios. 
contrario a la naturaleza de Dios. Desde esta perspectiva, el acercamiento entre la fe y razón deben darse según los términos del Concilio de Calcedonia (451) cuando definía la recta ortodoxia sobre la verdadera naturaleza de Cristo frente al monofisismo de Eutiques: "sin confusión, sin cambio, sin división, sin separación". La fe ilumina a la razón en la búsqueda de sentido de la vida del hombre y la razón le permite a la fe su propia explicitación, descartando de ella misma el error y la contradicción. Así, lo que emerge claramente en las palabras del Papa es que la razón necesita ser purificada por la fe y esto vale también para la razón política, que no debe creerse omnipotente. A su vez, la religión tiene siempre necesidad de ser purificada por la razón para mostrar su auténtico rostro humano. La ruptura de este diálogo comporta un coste muy gravoso para el desarrollo de la humanidad (CV 56).

\section{REFERENCIAS}

Benedicto XVI (2009) Encíclica Caritas in veritate. Lima, Ediciones Paulinas.

Bobadilla Rodríguez, Francisco y Ortega Suárez, Gabriela. (2009). Progreso económico y desarrollo humano: 40 años después de la Populorum Progressio. Piura, UDEP.
Brzezinski, Zbigniew. (1998). El gran tablero mundial: la supremacía estadounidense y sus imperativos geoestratégicos. Barcelona, Paidós.

Concilio Ecuménico Vaticano II. (1965) Constitución Pastoral Gaudium et Spes.

Cortés, Julio. (1992) El Corán. 4ta. ed. Barcelona, Herder.

Herr, Theodor. (1990) Doctrina Social Católica. V. Hase E Koehler Verlag Mainz, Germany.

Laurent, Eric. (1991). Tormenta del desierto: Los secretos de la Casa Blanca. Badalona, Ediciones Tempestad.

Lleonart, A. (1991) La anunciada guerra del Golfo. Madrid, Ediciones Década-90.

Mifsud S. J. Tony. (1986) Moral Social. Tomo IV. Santiago de Chile, Paulinas.

Ratzinger, Joseph. (2005). Fe, verdad y tolerancia: el cristianismo y las religiones del mundo. 2da ed. Salamanca, Sígueme.

Varea, Carlos y Maestro, Ángeles (edit). (1997). Guerra y sanciones a Irak: Naciones Unidas y el "nuevo orden mundial". Madrid, Los Libros de la Catarata. 